\title{
KELIMPAHAN JENIS FITOPLANKTON DI INLET DAN OUTLET WADUK BENING SEBAGAI BAHAN PENYUSUN MEDIA PEMBELAJARAN BERBENTUK POSTER
}

\author{
Andhi Bayu Priambodo \\ SMPN 2 Satu Atap Jambon, Ponorogo \\ Email: casillas_andhy01@yahoo.com \\ Diterima 3 Desember 2014 disetujui 20 Februari 2015
}

\begin{abstract}
This study aimed to determine the abundance of phytoplankton in the waters of the inlet and outlet Reservoirs Bening. Hamlet Village Petung Pajaran Saradan District of Madison County as well as exploit some results of research on the abundance of phytoplankton as a medium of learning materials were shaped poster on the types of phytoplankton. This study uses the exploratory research is directly done by observing and identifying body shapes, locomotor and body color that is in the phytoplankton Reservoir Bening in the inlet and outlet by taking samples at two points each station with three replications samples. Phytoplankton that have been filtered observed under the microscope and then identified the species and grade as well as documented. Calculated amount of phytoplankton abundance at each inlet and outlet areas. The results showed that the abundance of phytoplankton in the inlet and outlet. Phytoplankton abundance in the inlet area of the Month December to February respectively is $330 \mathrm{ind} / 1,286.291 \mathrm{ind} / 1$, and 258.892 ind/l, while the abundance of phytoplankton in the area of the outlet of the Month December to February respectively Tutut 130.844 ind/1, 112.200 ind/l, and 98.430 ind/l. Phytoplankton species in the Reservoir Bening Saradan found 12 species of phytoplankton that is, Synedra ulna, Tetragonodium verum, Synedra acus, Surirella elegans, Ceratium, Surirella sp, Pediastrum simplex, Chlorocytrium lemnae, Nitzia palea, Crucigenia rectangularis, grevillei Navicula, Scenedesmus acumatus. Phytoplankton abundance is the most ubiquitous class Bacillariophyceae species Synedra acus.
\end{abstract}

Kata kunci: phytoplankton, abundance, inlet and outlet

\section{PENDAHULUAN}

Ekosistem perairan mempunyai peran pokok dalam menjaga keseimbangan kehidupan organisme yang hidup. Banyak faktor yang saling berkaitan dan mempengaruhi keberlangsungan hidup organisme air. Salah satu faktor biologi yang mempengaruhinya adalah kehidupan plankton.

Plankton dapat dibagi menjadi dua golongan utama yaitu fitoplankton dan zooplankton. Fitoplankton termasuk jenis tumbuhan yang banyak ditemukan di semua perairan, tetapi karena ukurannya mikroskopis sukar dilihat kehadirannya (Anugerah, 2005: 127).

Keberadaan, kelimpahan, dan keanekaragaman fitoplankton dapat dijadikan indikasi perubahan ekosistem yang ada di suatu waduk. Menurut Sastrawijaya (dalam Melsy: 2012) fitoplankton dapat dijadikan indikator biologi dalam pencemaran air. Bila keanekaragaman Fitoplankton di ekosistem tinggi menandakan kualitas air baik dan bila keanekaragaman Fitoplankton sedikit menandakan air tercemar, selain itu dapat dipengaruhi oleh faktor fisika kimia yang meliputi suhu, $\mathrm{pH}$, DO, kecepatan arus, dan $\mathrm{CO} 2$ bebas. Kesemua faktor tersebut saling berkaitan dan berhubungan antara faktor yang satu dengan yang lain. Menurut Adnan, dkk; (2009:50) inlet adalah merupakan kawasan tempat aliran air masuk yang berhubungan dengan sungai, sedangkan outlet adalah kawasan yang merupakan tempat air keluar dari waduk.

Salah satu jenis waduk yang 
terkenal di daerah perbatasan Kabupaten Madiun dan Kabupaten Nganjuk, di Desa Pajaran, Kecamatan Sadaran adalah Waduk Bening. Waduk Bening memiliki luas $860 \mathrm{~km} 2$. Beberapa aktivitas yang dilakukan oleh masyarakat di daerah inlet dan outlet Waduk Bening secara tidak langsung berpengaruh pada kelestarian ekosistem perairan khususnya kelimpahan fitoplankton.

Menurut Rimper (dalam Yaserli, dkk., 2013) kelimpahan fitoplankton terbagi atas 3 kelompok fitoplankton yaitu rendah, sedang dan tinggi. Kelimpahan rendah berkisar $<12.000$ sel/1, sedang $12.500 \mathrm{sel} / 1$ dan kelimpahan fitoplankton tinggi $>17.000 \mathrm{sel} / 1$. Jumlah spesies dan kelimpahan yang bervariasi mempengaruhi indeks keanekaragamannya.

Kelimpahan fitoplankton di daerah inlet dan outlet berbeda, karena perbedaaan unsur hara, arus, dan zooplankton yang ada selain faktor fisik dan kimia dalam perairan. Hasil penelitian R. Dondajewska, et al; (2008: 2229) menunjukkan bahwa rata-rata kelimpahan fitoplankton di Inlet sebesar 14960 sel ml-1 sedangkan di outlet sebesar 9337 sel ml-1.

Sebagian hasil penelitian fitoplankton yang dilakukan di Waduk Bening akan disusun dalam media pembelajaran poster. Tujuannya untuk memudahkan masyarakat secara umum mengetahui jenis-jenis fitoplankton yang terdapat di Waduk Bening. Poster merupakan media grafis dengan ciri spesifik yakni media dua dimensi yang hanya dapat dilihat dari bagian depannya saja, sehingga hanya dapat diterima melalui indera mata (I Wayan 2010: 11). Mukminan dan Saliman (2008:13) mengatakan bahwa poster merupakan suatu kombinasi visual yang terdiri dari garis, warna dan katakata yang dimaksudkan untuk menarik perhatian dari kejauhan dalam rangka mengkomunikasikan suatu pesan pendek.

\section{METODE PENELITIAN}

Lokasi penelitian pengambilan sampel adalah di Waduk Bening Desa Pajaran Kecamatan Saradan Kabupaten
Madiun Provinsi Jawa Timur. Waduk Bening oleh masyarakat difungsikan untuk aktivitas pertanian, PLTA, perikanan, wisata, camping dan ritual budaya. Identifikasi dan penghitungan kelimpahan fitoplankton dilakukan di Laboratoriun Fakultas Pendidikan Matematika dan Ilmu Pengetahuan Alam Progam Studi Pendidikan Biologi IKIP PGRI Madiun. Penelitian dimulai bulan Desember 2013 Februari 2014.

\section{Prosedur Pengambilan Sampel}

Langkah-langkah pengambilan sampel adalah sebagai berikut. Alat yang digunakan yakni plankton net $80 \mu \mathrm{m}$, botol flakon, botol gelap, ember 3 liter, bolpoin. Bahan yang digunakan yakni formalin 4\%.

Prosedur kerja yang digunakan yakni mengambil sampel air secara vertikal dan horizontal dapat dilakukan dengan ember plastik kapasitas 3 liter. Sampel diambil sebanyak 30 liter dan disaring dengan jaring plankton (plankton net). Air yang tertampung dalam botol penampung dipindahkan ke dalam botol flakon yang bersih, berlabel dan diberi larutan pengawet formalin 4\% (Satino, 2010: 17).

\section{Analisis Hasil Samping}

Kegiatan pengamatan fitoplankton dilakukan di Laboratoriun Biologi IKIP PGRI Madiun. Prosedur pengamatan fitoplankton adalah sebagai berikut: menyiapkan peralatan yang akan digunakan, mengambil sampel dengan menggunakan pipet tetes, meneteskan air pada objek glass, kemudian ditutup menggunakan cover glass, mengamati fitoplankton menggunakan mikroskop binokuler.Kegiatanidentifikasifitoplankton dilakukan di Laboratoriun Biologi IKIP PGRI Madiun. Identifikasi fitoplankton melalui bentuk tubuh berbentuk koloni dan multiseluler, adanya dinding sel atau cangkang (Kimball, dalam Linda dan Trisna 2009: 2). Alat gerak fitoplankton ada yang bergerak aktif dan ada yang tidak, jenisjenis yang dapat bergerak aktif mempunyai alat untuk bergerak yang berupa bulu-bulu cambuk atau flagel (Gembong, 2005: 30). 
Penentuan kelimpahan fitoplankton dihitung menggunakan rumus menurut Sachlan dan Effendie (dalam Madinawati, 2010: 120) yakni :

$$
\mathrm{N}=\mathrm{n} \times\left(\frac{\mathrm{Vr}}{\mathrm{Vo}_{\mathrm{o}}}\right) \times\left(\frac{1}{\mathrm{VS}_{\mathrm{S}}}\right)
$$

\section{Dimana}

$\mathrm{N}=$ Jumlah sel per liter (ind/l)

$\mathrm{N}=$ Jumlah sel yang diamati atau didapat

$\mathrm{Vr} \quad=$ Volume air tersaring $(\mathrm{ml})$

Vo = Volume air yang diamati $(\mathrm{ml})$

Vs =Volume air yang disaring (1)

\section{HASIL DAN PEMBAHASAN}

Hasil perhitungan rata-rata kelimpahan fitoplankton di Waduk Bening dengan masing-masing dilakukan 3 kali pengulangan dapat diamati pada Gambar 1 berikut

ini.

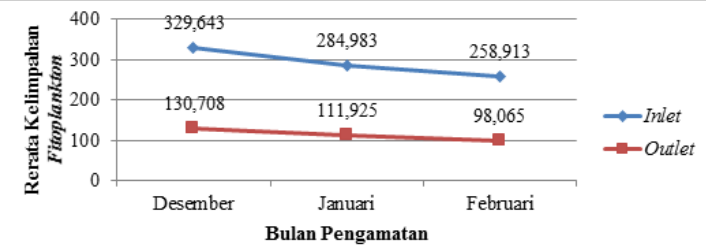

Gambar1. Kelimpahan Fitolankton di Inlet dan Outlet Waduk Bening

Gambar 1 merupakan rata-rata kelimpahan fitoplankton daerah inlet dan outlet di Waduk Bening selama bulan Desember - Februari 2014. Rata-rata kelimpahan fitoplankton pada daerah inlet di bulan Desember sampai bulan Februari secara berturut adalah 329,643 ind/1, 284,983 ind/l, dan 258,913 ind/1. Perbedaan yang sangat jauh terdapat pada daerah outlet di bulan Desember sampai Februari secara berturut adalah 130,708 ind/1, 111,925 ind/1, dan 98,065 ind/1. Ratarata kelimpahan fitoplankton di daerah inlet lebih tinggi dari pada di daerah outlet tiap bulannya. Hasil rata-rata kelimpahan fitoplankton $<12.000 \mathrm{sel} / 1$ dan tergolong kelimpahan rendah. Sesuai dengan pendapat Rimper (dalam Yaserli, dkk., 2013) yang mengatakan bahwa kelimpahan fitoplankton rendah berkisar $<12.000 \mathrm{sel} / 1$.
Kelimpahan fitoplankton di daerah inlet selama bulan Desember - Februari 2014 memiliki kelimpahan yang tinggi dibandingkan dengan daerah outlet. Tingginya kelimpahan fitoplankton di daerah inlet dikarenakan pada daerah ini merupakan sumber air masuk yang banyak membawa hara. Sumber hara ini berasal dari aktivitas pertanian yang memiliki kandungan $\mathrm{N}$, $\mathrm{P}$, dan $\mathrm{K}$ yang banyak meningkatkan unsur hara di dalam perairan, sehingga akan mempercepat pertumbuhan fitoplankton. Diperkuat dengan penelitian Adnan, dkk., (2009: 55) bahwa hara yang tinggi berbanding lurus dengan kelimpahan fitoplankton yang ada di Waduk Nagedang. Berbeda di daerah outlet kelimpahan fitoplankton lebih sedikit karena pada daerah ini merupakan kawasan air keluar perairan Waduk Bening sehingga arus air membawa fitoplankton keluar waduk, sehingga dimungkinkan fitoplankton bisa terbawa arus keluar dari waduk.

Data spesies fitoplankton di inlet dan outlet Waduk Bening dapat digunakan untuk melihat spesies fitoplankton yang ada dan yang dominan di perairan Waduk Bening.

Spesies yang terdapat di Waduk Bening daerah inlet dan outlet dapat dilihat pada tabel 4.2 berikut. Tabel 4.2 menunjukkan spesies fitoplankton yang mendominasi berasal dari kelas Bacillariophyceae dengan spesies Synedra acus yang jumlahnya 998 dan spesies Synedra ulna yang jumlahnya 953 Bacillariophyceae dengan spesies Synedra acus yang jumlahnya 998 dan spesies Synedra ulna yang jumlahnya 953

Data fisika-kimia digunakan sebagai parameter kualitas air di Waduk Bening. Data ini digunakan sebagai pendukung kelimpahan fitoplankton di inlet dan outlet Waduk Bening. 
Priambodo

\begin{tabular}{clccc}
\hline \multicolumn{1}{c}{ Tabel 4.2 Data Kelimpahan Spesies Fitoplankton di Waduk Bening } & & \\
\hline \multicolumn{1}{c}{ Kelas } & Spesies & $\Sigma$ Inlet & $\Sigma$ Outlet & $\Sigma$ Total \\
\hline Bacillariophyceae & Synedra ulna & 714 & 239 & 953 \\
& Synedra acus & 703 & 295 & 998 \\
& Surirella elegans & 30 & 21 & 51 \\
& Surirella sp & 23 & 13 & 46 \\
& Nitzia palea & 6 & 12 & 18 \\
& Navicula grevillei & 7 & 4 & 11 \\
hlorophyceae & Pediastrum simplex & 13 & 6 & 19 \\
& Chlorocytrium lemnae & 10 & 4 & 14 \\
& Crucigenia rectangularis & 6 & 1 & 7 \\
Chryptophyceae & Scenedesmus acuminatus & 7 & 0 & 7 \\
Dinophycea & Tetragonodium verum & 31 & 19 & 40 \\
& Ceratium hirudinella & 22 & 6 & 28 \\
\hline
\end{tabular}

Tabel 4.2 menunjukkan spesies fitoplankton yang mendominasi berasal dari kelas Tabel 4.3 Sifat Fisika-Kimia Perairan Waduk Bening

\begin{tabular}{|c|c|c|c|c|c|c|}
\hline No & Bulan & Stasiun & Suhu Air & $\begin{array}{l}\text { Suhu } \\
\text { Udara } \\
\end{array}$ & $\mathrm{pH}$ & $\mathrm{DO}$ \\
\hline \multirow{2}{*}{1} & \multirow{2}{*}{ Desember } & IN & $28,750 \mathrm{C}$ & $320 \mathrm{C}$ & 8,35 & 10,6 \\
\hline & & OUT & $290 \mathrm{C}$ & $32,50 \mathrm{C}$ & 5,55 & 11,2 \\
\hline \multirow{2}{*}{2} & \multirow{2}{*}{ Januari } & IN & $26,50 \mathrm{C}$ & $27,50 \mathrm{C}$ & 7,1 & 8,5 \\
\hline & & OUT & $27,50 \mathrm{C}$ & $26,750 \mathrm{C}$ & 7,75 & 9 \\
\hline \multirow{2}{*}{3} & \multirow{2}{*}{ Februari } & IN & $28,50 \mathrm{C}$ & $28,250 \mathrm{C}$ & 7,55 & 9,5 \\
\hline & & OUT & $29,50 \mathrm{C}$ & $290 \mathrm{C}$ & 7,8 & 9,5 \\
\hline
\end{tabular}

Tabel 4.3 menunjukkan sifat fisik- perbandingan kelimpahan menggunakan kimia di Waduk Bening selama bulan Desember-Februari 2014. Sifat fisik-kimia secara umum menunjang pertumbuhan fitoplankton. Nilai $\mathrm{pH}$ di Waduk Bening 5,55 - 8,35 masih menunjang untuk pertumbuhan fitoplankton. Menurut Kordi (dalam Adnan dkk, 2009) menyatakan bahwa derajat keasaman yang ideal adalah $4,00-9,00$. Hasil pengukuran DO selama 3 bulan menunjukkan nilai yang baik untuk kehidupan mahluk hidup akuatik yaitu 8,5 - 11,2. Wardoyo (dalam Adnan, dkk., 2009: 56) menyatakan bahwa perairan yang normal untuk kehidupan akuatik, kandungan oksigen terlarut dalam air tidak boleh kurang dari 2 ppm. Didukung dengan hasil pengukuran suhu air dan suhu udara yang cukup baik dalam perairan di Waduk Bening yaitu $(26,5$ - 32,5).

Penelitian kelimpahan fitoplankton dilakukan bulan Desember - Februari 2014. Pada penelitian ini diambil rata-rata kelimpahan fitoplankton di daerah inlet dan outlet, dari hasil rata-rata diambil statistik nonparametrik. Hasil uji MannWhitney menunjukkan bahwa peringkat rata-rata kelimpahan fitoplankton di lokasi inlet lebih tinggi yaitu 14.00 dari pada peringkat di lokasi outlet yaitu 5.00. Nilai U sebesar 0.000 dan nilai $W$ sebesar 45.000. Signifikan dapat dilihat pada nilai $p$ value $<$ batas kritis 0,05 . Hasil tersebut dikatakan bahwa ada perbedaan yang bermakna antara kelimpahan fitoplankton di dua lokasi inlet dan outlet.

\section{SIMPULAN}

Rata-rata kelimpahan fitoplankton di Waduk Bening daerah inlet lebih tinggi yaitu 291,179 Ind/1 dari pada daerah outlet yaitu 113,566 Ind/1, terdapat perbedaan yang nyata antara kelimpahan fitoplankton di daerah inlet dan outlet Waduk Bening dengan nilai signifikasi 0,00 , dan sebagian hasil penelitian kelimpahan fitoplankton di daerah inlet dan outlet Waduk Bening dapat digunakan sebagai bahan penyusunan 
media pembelajaran berbentuk poster.

\section{DAFTAR PUSTAKA}

Adnan, Eni, dan Heriyanto. 2009. Kesuburan Perairan waduk Nagedang Ditinjau dari Konsentrasi Klorofil-a Fitoplankton Desa Giri sako Kecamatan Logas Tanah darat Kabupaten Kuantan Singingi Provinsi Riau.Berkala Perikanan Terubuk, Vol. 37 No. 2 (Online),48-59 Anugerah Nontji. 2005. Laut Nusantara. Jakarta: Ikrar Mandiriabadi.

Gembong Tjitrosoepomo. 2005. Taksonomi Tumbuhan. Yogyakarta: Gadjah mada University Press.

I Wayan Santyasa. 2001. Landasan Konseptual Media Pembelajaran. Makalah Disajikan dalam Workshop MediaPembelajaranbagiGuru-Guru SMA Negeri Banjar Angkan. Bali: Universitas Pendidikan Ganesha. (http://www.worksopmedia.ganesha. ac.id, Diunduh 15 Januari 2014).

Madinawati. 2010. Kelimpahan dan Keanekaragaman Plankton Di Perairan Laguna Desa Tolongano Kecamatan Banawa Selatan. Media Litbang Sulteng III (Online), (http:// medialitbang.ac.id, Diunduh 13 Januari 2014)

Melsy Hasmaini, Nursyahra dan Armein Lusi Z. 2012. Komposisi Fitoplankton Di Muara Pasir Baru Kanagarian Pilubang Kecamatan Sungai Limau Kabupaten Padang Pariaman: Jurnal MIPA (Online), (http://ejournal.STKIPPGRI.ac.id , Diunduh 27 Januari 2014).

Mukminan dan Saliman. 2008. Teknologi Informasi Dan Pengembangan Media Pembelajaran IPS (Ilmu Pengetahuan Sosial). Modul Untuk Pelatihan IPS Terpadu Bagi Guru IPS SMP Di FISE-UNY (Online), (http://modul ips.uny.ac.id, Diunduh 15 Januari 2014).

R. Dondajewska, M. Blajet, dan A.kazek. 2007. Changes in Phytoplankton Composition as a Result of Water Flow through a Shallow Lowland
Reservoir. 22282-2232, (http://www. sciencedirect.com, Diunduh 16 Januari 2014).

Satino. 2010. Acuan Praktikum Limnologi. Petunjuk Praktikum Limnologi (Online), (http://modul limnologi. uny.ac.id, Diunduh 13 Januari 2014) Yaserli, Syafril, dan Efawani. 2013. Keragaman Fitoplankton di Perairan Danau Singkarak, Jorong Ombilin Rambatan Sub-Regency, Kabupaten Tanah Datar, Provinsi Sumatera Barat. Jurnal MIPA (Online), (http:// http://ojs.unud.ac.id/index.php/blje/ article/view/2423/1651, Diunduh 16 Januari 2014). 